\title{
Calorimetry in the studies of by-pass cement kiln dust as an additive to the calcium aluminate cement
}

\author{
Wiesława Nocuń-Wczelik ${ }^{1} \cdot K^{\prime}$ atarzyna Stolarska ${ }^{1}$
}

Received: 13 November 2018 / Accepted: 11 October 2019 / Published online: 2 November 2019

(c) The Author(s) 2019

\begin{abstract}
The studies focused on the kinetics of early hydration in the high-calcium aluminate cement (CAC 70)_by-pass cement kiln dusts (BPCKD) - mixtures. For this purpose, the mixtures of cement with this additive or with some potential constituents of dusts were produced. The microcalorimeter was applied to follow the kinetics of hydration. The investigations with the aim of finding the relationship between the components of initial mixtures and the modification of hydration process were carried out. The rheological properties were characterized, and the chemical shrinkage characteristics were produced. The phase assemblage characterization and microscopic observations were done as well. In case of the high-calcium aluminatebased binders, the modification of setting process was observed; the rheological properties and chemical shrinkage were affected too. The acceleration of heat evolution-the shortening of so-called induction period in the presence of BPCKD additive-was observed. The results were compared to those obtained for the CAC with ordinary Portland cement additive. The results of calorimetric measurements are discussed in terms of the chemical and phase assemblage of this additive as compared to the Portland cement clinker precursors and potassium chloride-the solid and liquid components of the dust.
\end{abstract}

Keywords Calcium aluminate cement $\cdot$ Hydration $\cdot$ By-pass cement kiln dust $\cdot \mathrm{KCl}$, calorimetry $\cdot$ Rheological properties $\cdot$ Microstructure $\cdot$ Chemical shrinkage

\section{Introduction}

Monocalcium aluminate phase $\mathrm{CaO} \cdot \mathrm{Al}_{2} \mathrm{O}_{3}-\mathrm{CA}$ (notation commonly used in cement chemistry: $\mathrm{C}=\mathrm{CaO}, \mathrm{A}=\mathrm{Al}_{2} \mathrm{O}_{3}$, $\mathrm{H}=\mathrm{H}_{2} \mathrm{O}$ ) is the principal phase in aluminate cements [1]. The compound corresponding to the formula $12 \mathrm{CaO} \cdot 7 \mathrm{Al}_{2} \mathrm{O}_{3}$ is the second aluminate phase. On reaction with water at ambient temperature, a setting and hardening of calcium aluminate paste take place and the hydrated calcium aluminate phases, such as $\mathrm{CaO} \cdot \mathrm{Al}_{2} \mathrm{O}_{3} \cdot 10 \mathrm{H}_{2} \mathrm{O}-\mathrm{CAH}_{10}, 2 \mathrm{CaO} \cdot \mathrm{Al}_{2} \mathrm{O}_{3} \cdot 8$ $\mathrm{H}_{2} \mathrm{O}-\mathrm{C}_{2} \mathrm{AH}_{8}$ (hexagonal hydrates) and aluminum hydroxide $\left(\mathrm{AH}_{3}\right)$, are formed [1-3]. However, further transformation of hexagonal hydrates into the thermodynamically stable cubic one $\left(\mathrm{C}_{3} \mathrm{AH}_{6}\right)$, known as "conversion," leads to the destruction of hardened material because of the release of water and formation of $\mathrm{AH}_{3}$ gel.

Wiesława Nocuń-Wczelik

wiesia@agh.edu.pl

1 University of Science and Technology AGH, al. Mickiewicza 30, 30-059 Kraków, Poland
High-calcium aluminate cements can be used in combination with different calcium sulfate or calcium silicate sources as a binder for special purposes [4-6]. Hydration and setting of Portland cement mixed with a few percent of high alumina cement occur rapidly, and the significant strength development within a few hours is observed [5, 6]. This mixture was utilized in various applications, such as sealing of leaks, rapid road pavement repair and waste solidification. It is known that the shrinkage compensation or even the controlled expansion is thus achieved due to the ettringite formed as the hydration product. The hydration development at early ages is significant [7].

Different metallic salts, when added to hydrating CAC paste, result in the modification of hydration kinetics in different ways: Acceleration (strong or slight) or retardation of hydration process is observed, depending on the nature of cations and anions, as well as the concentration [8]. The possibility to form the complex compounds is of importance too $[8,9]$.

The additives of pozzolanic or hydraulic character replacing part of high alumina cement can reduce the hexagonal hydrate conversion and its negative effects, first of all the 
volume changes and strength reduction. The reactive silica released from these additives enters the hydration process, and the so-called strätlingite phase $\mathrm{C}_{2} \mathrm{ASH}_{8}$ is produced [9-15].

Cement kiln by-pass dust (BPCKD) is produced as a solid waste from the by-pass systems during the manufacture of Portland cement clinker, by using dry process [16]. By-pass dust, being the precursor of cement clinker phases, is rejected from a kiln system in order to lower the chlorine and alkali content in the final product; these components are evaporated from the raw feed at higher temperatures (clinker sintering occurs at approx. $1450{ }^{\circ} \mathrm{C}$ ). The composition of cement kiln by-pass dust depends on the type of raw materials and the fuel used, as well as the production method or kiln type; an increase in alternative fuels may cause an increase in by-pass dust emission.

Many cement plants have routinely landfilled this dust over many years; however, with the increasing need to recycle industrial by-products and protect the environment, an option for the utilization of the by-pass dust is mixing with other construction materials such as the other binders or usage for the solidification of soils, in road construction, etc., was taken into account. Therefore, there is a growing emphasis to provide technical data about the performance of materials containing cement by-pass dust (CBPD); and they can be potentially used for various types of commercial applications [17]. These applications depend primarily on the chemical and physical characteristics.

Recently, the use of both high-calcium aluminate material and the by-products of different origins are discussed from the "environmental footprint" point of view [13, 14, $18,19]$. It has been found that usage of CAC as a component of different dry mixtures demonstrates significant environmental benefits in terms of environmental impact (low $\mathrm{CO}_{2}$ emission, low energy demand vs. early compressive strength, etc.) [18]. The experiments presented in this paper were done with aim to make a comparison between the modifying action of Portland cement in the hydration process of high-calcium aluminate cement (recognized) and the effect of cement kiln by-pass dust in the same process (unknown). The results of these studies are the base for more practical projects, dealing with BBPD disposal and improvement of some special binders.

\section{Experimental procedure}

\section{Materials and method}

The by-pass cement kiln dust (BPCKD), ordinary Portland cement (OPC) and calcium aluminate cement (CAC70) samples used in this study were supplied by cement plants. The specific surface of cements was 3120 and $3160 \mathrm{~cm}^{2} \mathrm{~g}^{-1}$ (as measured by Blaine method), respectively. The specific surface of by-pass cement kiln dust was $9550 \mathrm{~cm}^{2} \mathrm{~g}^{-1}$. The chemical composition is given in Table 1.

As one can find from the data presented in Table 1, the chemical composition of Portland cement and by-pass dust is very similar. However, a significant amount of potassium chloride should be underlined-mean $\mathrm{KCl}$ content in the dust-approximately $7 \%$. The main phases present in the dust are as follows: larnite $\left(\mathrm{Ca}_{2} \mathrm{SiO}_{4}\right)$ - the precursor of main calcium silicate components of cement clinker, as well as sylvite $(\mathrm{KCl})$, aptitalite $\left(\mathrm{K}_{2} \mathrm{Na}\left(\mathrm{SO}_{4}\right)\right.$, some amounts of calcium oxide $(\mathrm{CaO})$, calcite, aragonite $\left(\mathrm{CaCO}_{3}\right)$ and forsterite $\left(\mathrm{Mg}_{2} \mathrm{SiO}_{4}\right)$.

The following compositions of samples were taken into account:

Table 1 Characteristics of samples

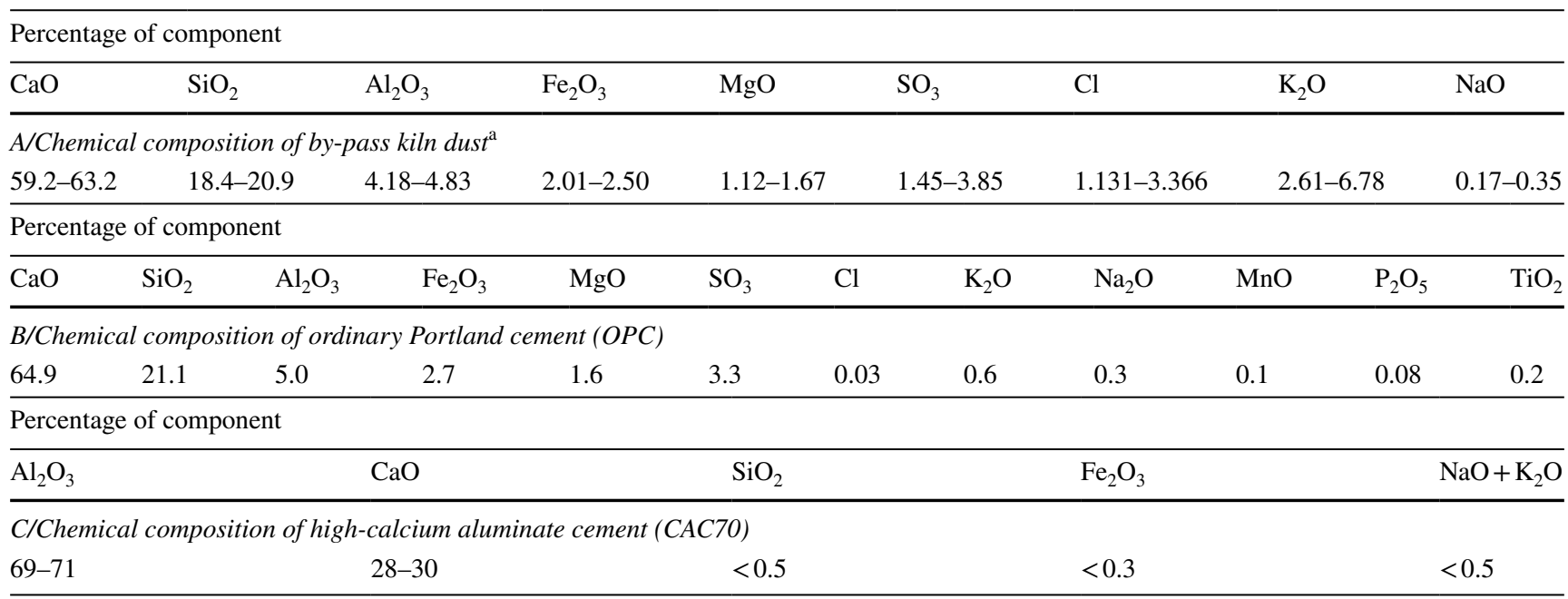

${ }^{\mathrm{a}}$ In figure captions the abbreviation BP is used 
Fig. 1 Rate of heat evolution (a-top) and heat of hardening (b-bottom) curves for cement pastes produced from highcalcium aluminate cements with additives $(w / c=0.5)$

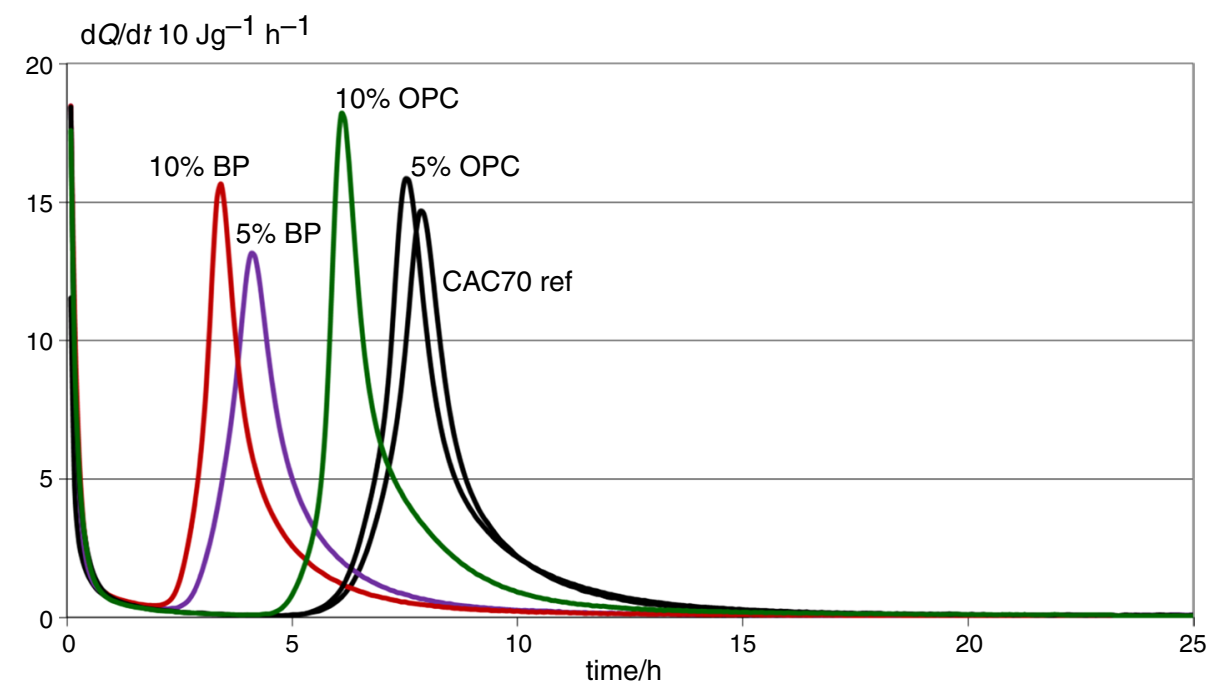

(a)

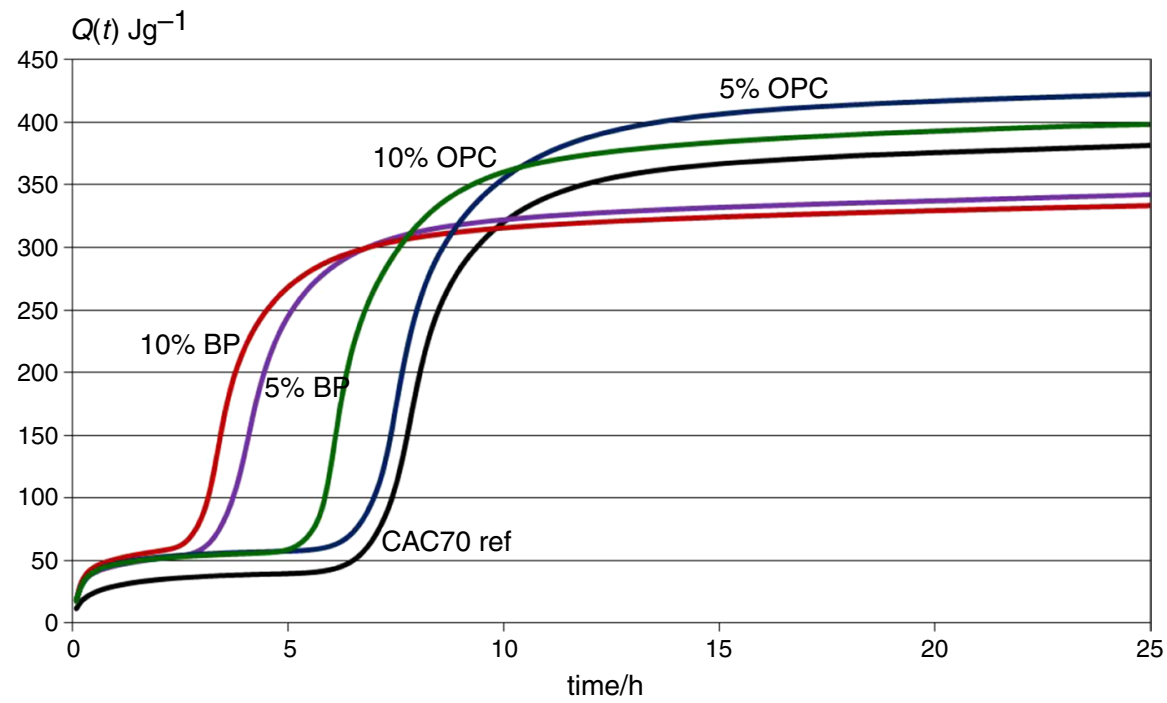

(b)

CAC70-reference

$\mathrm{CAC} 70+2 \%$ OPC; $\mathrm{CAC} 70+5 \%$ OPC; $\mathrm{CAC} 70+10 \%$ OPC;

$\mathrm{CAC} 70+2 \%$ OPC; $\mathrm{CAC} 70+5 \% \mathrm{BP} ; \mathrm{CAC} 70+10 \% \mathrm{BP}$; $\mathrm{CAC} 70$ in $0.01 \mathrm{~m} \mathrm{KCl}$; $\mathrm{CAC} 70$ in $0.1 \mathrm{~m} \mathrm{KCl}$; $\mathrm{CAC} 70$ in $1 \mathrm{~m} \mathrm{KCl}$

The following experiments were performed in this work:

Microcalorimetric evaluation of heat evolved during hydration,

Evaluation of chemical shrinkage,

Determination of phase assemblage of hydrated pastes by XRD

Studies of rheological properties by means of rotation viscometer,
Observations of microstructure.

The nonisothermal-nonadiabatic differential BMR microcalorimeter, constructed in the Institute of Physical Chemistry, Polish Academy of Science in Warsaw, with further modification (computing program, measurement of temperature) done in the laboratory at the University of Science and Technology AGH in Cracow, Poland, was used. Hydrating pastes were prepared by mixing of $5 \mathrm{~g}$ samples with $2.5 \mathrm{~mL}$ of water (water to solid ratio 0.5 ); and the initial temperature was kept constant at $25{ }^{\circ} \mathrm{C}$. The heat evolved values were measured with accuracy of $\pm 5 \mathrm{~J} \mathrm{~g}^{-1}$.

The chemical shrinkage was determined according to the ASTM C 1608-07 standard. This method is based upon the observation of upper level of water in the capillary placed above the hydrating paste $(w / s=0.4)$ sealed in a polystyrene container (the heights and diameter of containers differed 
Fig. 2 Rate of heat evolution (a-top) and heat of hardening (b-bottom) curves of cement pastes processed with $\mathrm{KCl}$ solution $(w / c=0.5)$

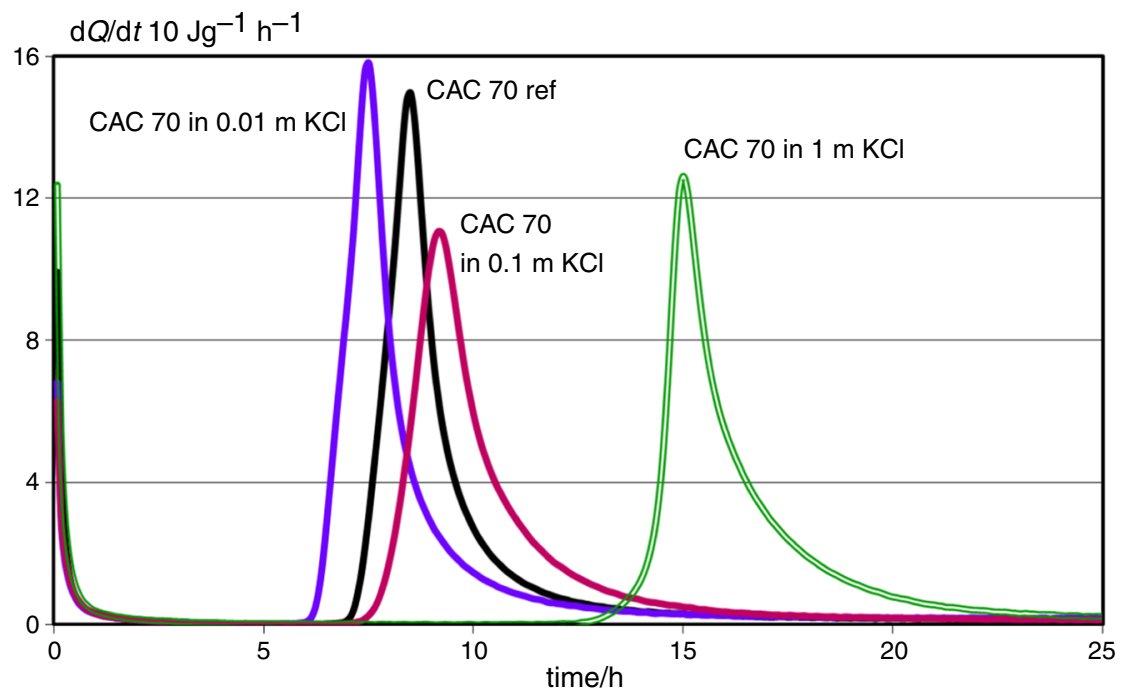

(a)

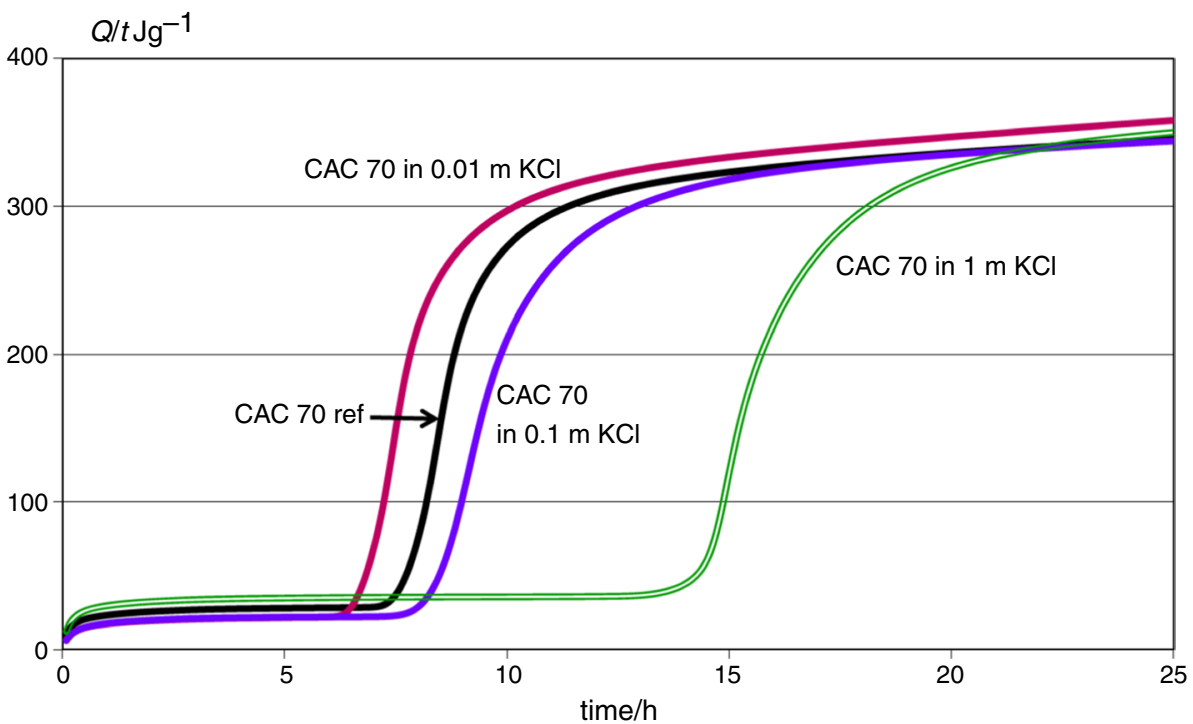

(b) slightly from those recommended in the standard). The "chemical shrinkage" means the volume of water consumed as a result of hydration reaction. These measurements reflect not only the kinetics of hydration but also the consumption of water to the structure of amorphous products.

The phase assemblage of hydrated pastes was characterized by XRD (XRD Philips diffractometer PW 1070 at $16 \mathrm{~mA} / 35 \mathrm{kV}$ current, with $\mathrm{Cu} \mathrm{K}_{\alpha}$ radiation), using the samples kept previously in the calorimeter $(w / s=0.5)$, after crushing and repeated washing with acetone to remove the residual, unbound water; the hydration was thus stopped. The powdered pastes were dried at $40{ }^{\circ} \mathrm{C}$.

The rheological parameters of pastes were determined with help of Rheotest 2 (Messgeräte Medinger GmbH, Germany). The flow curves of cement pastes with $w / s=0.4$ were obtained basing on the data from rheometer at increasing and decreasing yield stress. The rheological parameters, such as plastic viscosity $(\eta)$ and yield stress $\tau$ y, were determined from these curves.

Some samples were observed under SEM (FEINOVAnanoSEM 200 by Philips) with EDS Link-Isis microanalyzer, to characterize the microstructure and to identify the phases. The fractured samples after 3-day hardening, prepared at $w / s=0.4$, were examined; all the samples were subjected to the standard procedure of preparation (covered with gold in vacuum). 
Fig. 3 Chemical shrinkage of cement pastes with additives: ordinary Portland cement (OPC), by-pass kiln dust (BP) and processed with $\mathrm{KCl}$ solution $(w / c=0.4)$

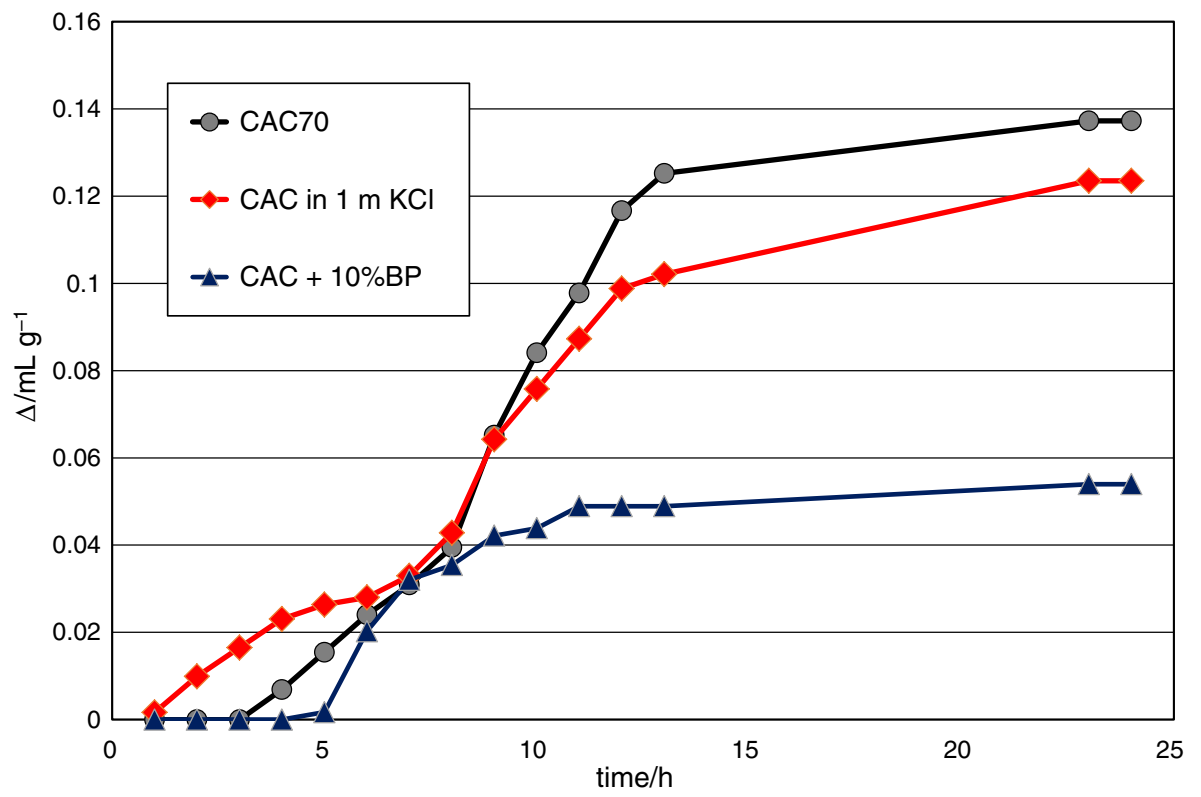

Fig. 4 XRD pattern of hydrated high-calcium aluminate cement samples admixtured with ordinary Portland cement (10\% OPC), by-pass kiln dust (10\% BP) and processed with $1 \mathrm{~m}$ $\mathrm{KCl}$ solution $(w / c=0.5)$, after 2-day storage in calorimeter

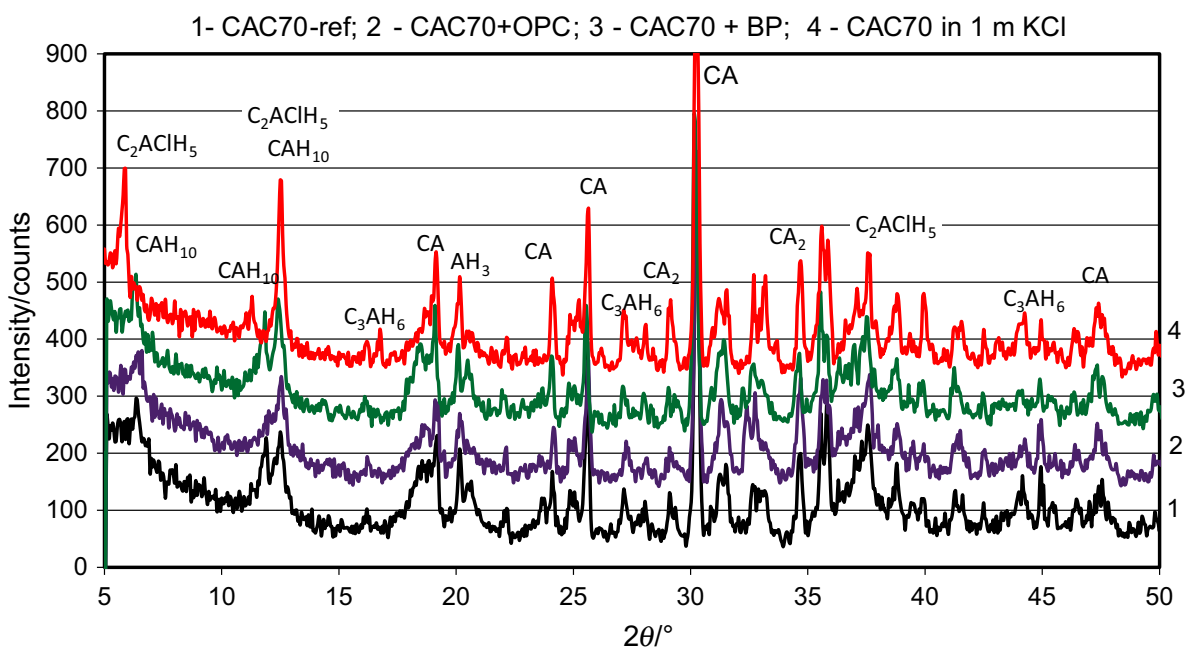

\section{Results}

The calorimetric measurements were the basis of further experiments. As it is commonly known, the calorimetric studies are of special importance in the determination of hydraulic activity of binders. Many crucial problems were resolved due to this method, not only in the case of Portland and blended cements but also in the case of CACs; some of them appeared quite recently [20-23].

The sets of calorimetric curves are shown in Figs. 1 and 2.

The reaction of calcium aluminate cements with water followed by calorimetry gives two strong peaks with socalled induction period between them; there is a few hours lasting latent period in which a dissolution of initial substance to attain the supersaturation of liquid phase and slow nucleation of less soluble hydration products takes place. Subsequently, the crystallization of hydrates takes place and the reaction with water is almost completed. The position of the second peak is attributed to the setting process, important from the practical point of view; the heat evolution reflecting standard setting and hardening must be completed within $24 \mathrm{~h}$.

As it can be noticed on heat evolution curves, the maximum of heat evolution rate in case of sample CAC70 is achieved within ca. 7-8 h, while for CAC70 with solid additives after shorter period of time (Fig. 1), particularly 
Fig. 5 Flow curves of cement pastes with additives: ordinary Portland cement (OPC), by-pass kiln dust (BP) and processed with $\mathrm{KCl}$ solution $(w / c=0.4)$

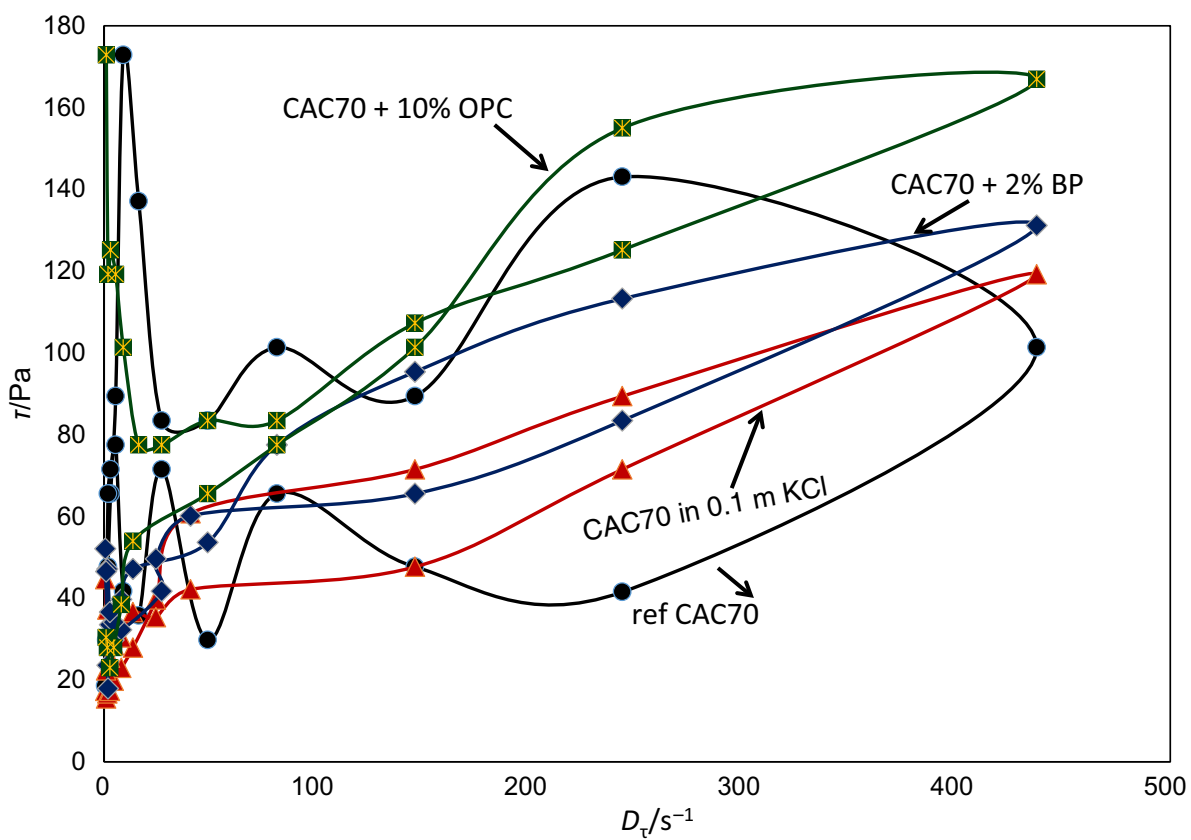

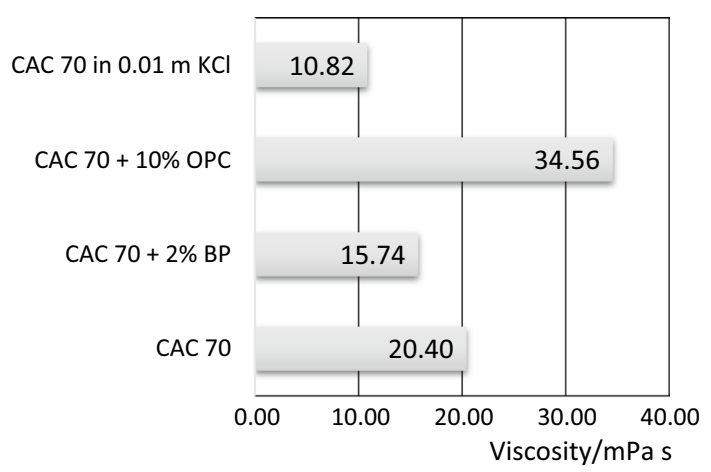

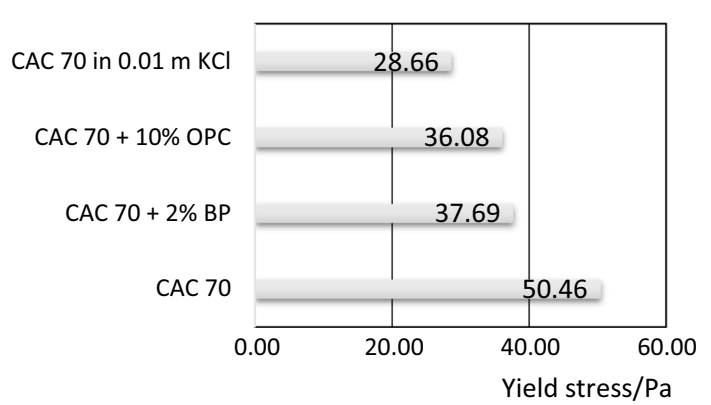

Fig. 6 Viscosity and yield stress of cement pastes with additives: ordinary Portland cement (OPC), by-pass kiln dust (BP) and processed with $\mathrm{KCl}$ solution $(w / c=0.4)$ as the by-pass dust is added. However, the total heat is the highest in case of OPC additive, presumably because of the ettringite phase formation [4-7]. The precursors of clinker do not cause such an effect; the acceleration would be the consequence of the soluble alkali salts occurrence. In order to verify this assumption, the calorimetric measurements of CAC samples processed with $\mathrm{KCl}$ solution were performed (Fig. 2). The lowest concentration-0.01 m-corresponds approximately to the level of $\mathrm{KCl}$ in the by-pass dust additive. In the case of $0.01 \mathrm{~m} \mathrm{KCl}$, the moderate acceleration of heat evolution is observed; however, at higher concentration, a retarding effect is seen, particularly when the hydration takes place in the $1 \mathrm{~m}$ solution. The so-called induction period is then very prolonged. However, the heat evolved values after $24 \mathrm{~h}$ are almost identical for all the CAC70 pastes hydrated with $\mathrm{KCl}$.

The measurements of chemical shrinkage (Fig. 3) reveal that the consumption of additional water by the hydrated paste alters when the CAC70 paste is enriched with by-pass dust or some amount of $\mathrm{KCl}$. The pastes show an "induction period" which is the longest in case of by-pass dust-presumably the structure is more impermeable because of the products formed with additive; after $5 \mathrm{~h}$, the formation of some consuming water products gives an additional space for water absorption. A more intensive water absorption is observed in the presence of $\mathrm{KCl}$. It should be noted that the "induction period" in this case is shorter than the induction period on the calorimetric curve.

The hydrated pastes were examined by XRD (Fig. 4; after 2-day hydration, the samples processed with water at $w / c=0.5$ were taken from the calorimeter and the procedure of unbound water removal was applied). Different phases 

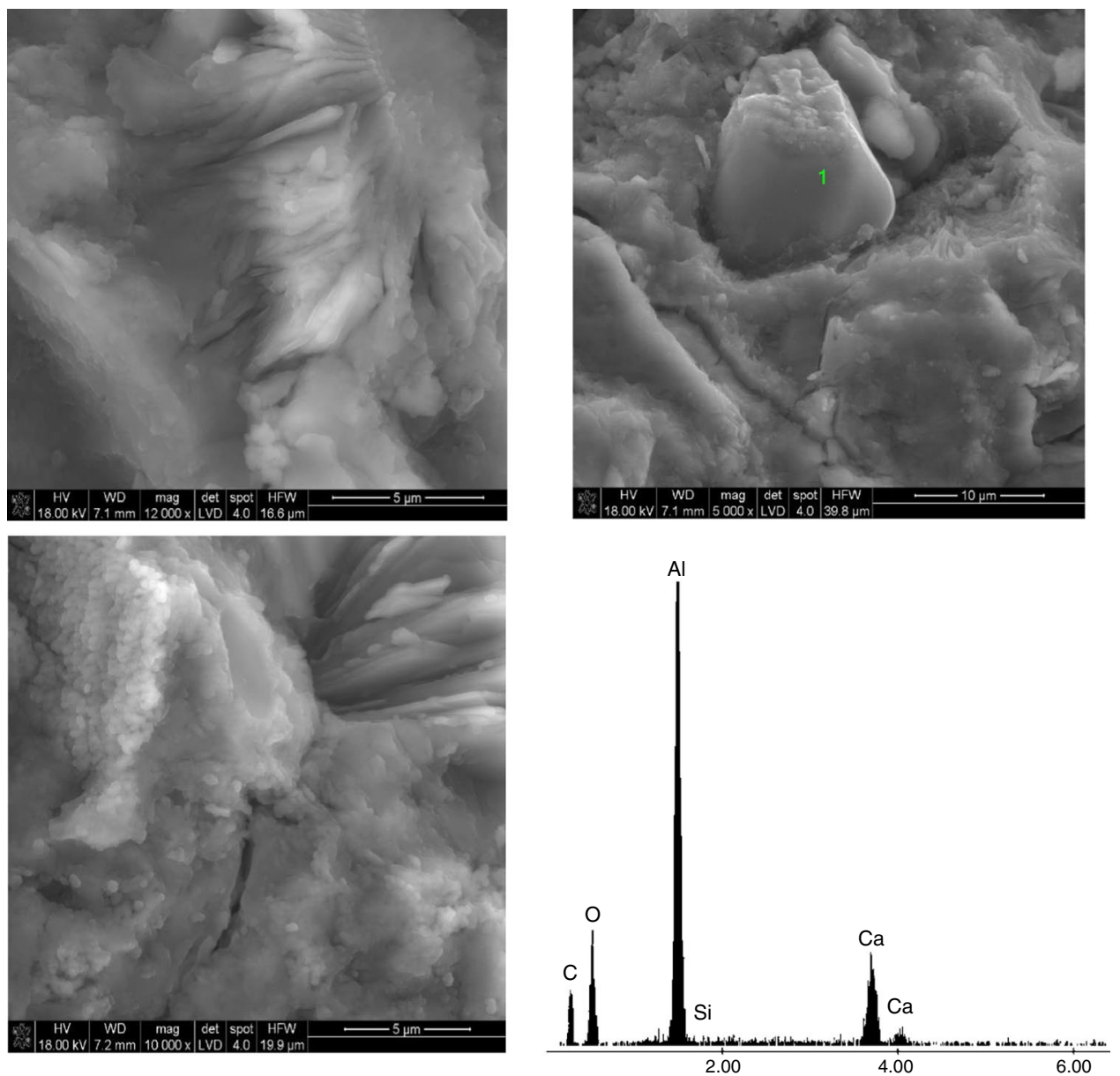

Fig. 7 Microstructure of cement paste with no admixture, after 3-day hardening $(w / s=0.5)$; the assemblages of hexagonal calcium aluminate hydrate plates are visible. EDS plot refers to the massive "granule" of aluminum hydroxide above
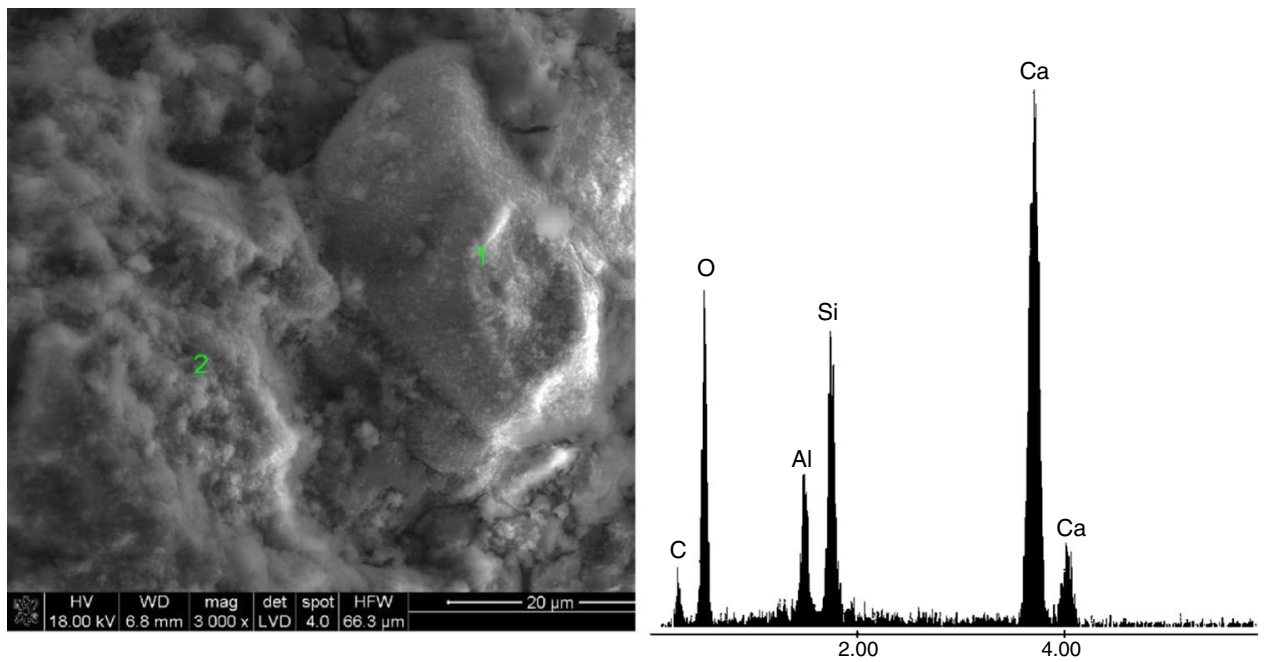

Fig. 8 Microstructure of cement pastes with by-pass kiln dust (BP) $(w / c=0.4)$ after 3-day hardening. See the calcium aluminosilicate hydrate product (strätlingite, right side of the illustration), as detected by EDS analysis 

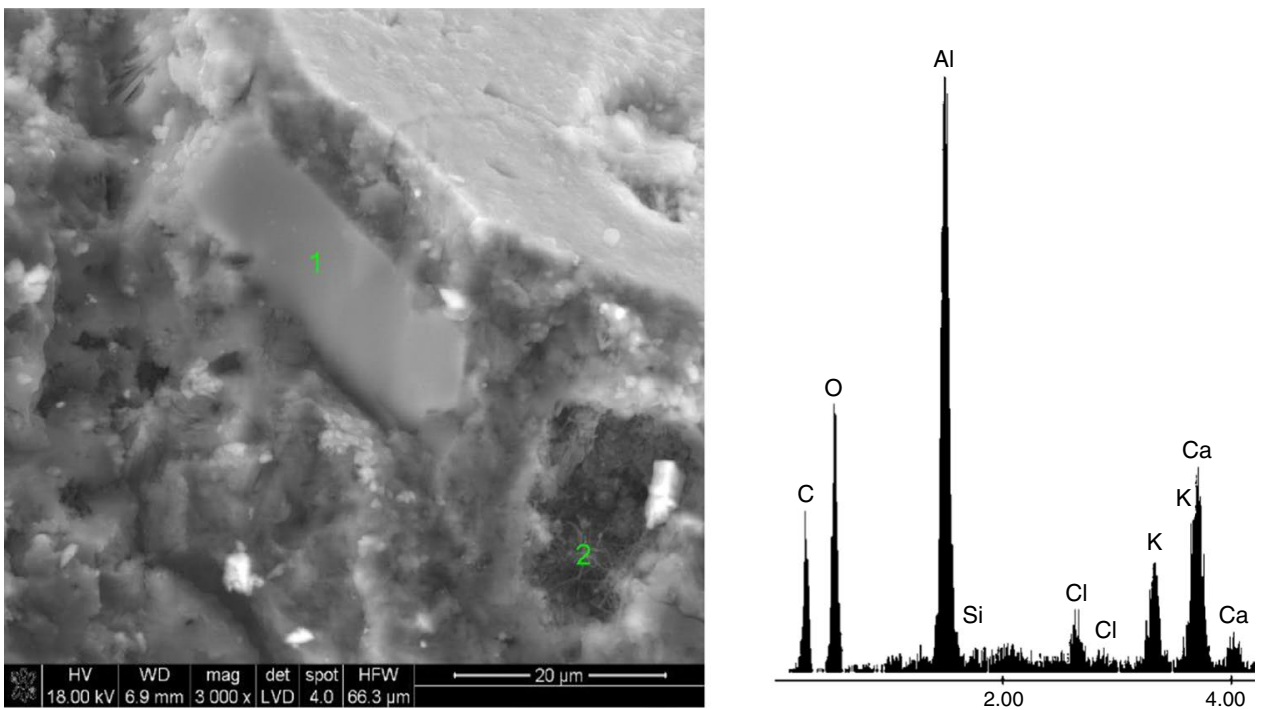

Fig. 9 Microstructure of cement pastes with by-pass kiln dust (BP) and processed with $\mathrm{KCl}$ solution $(w / c=0.4)$ after 3-day hardening. See the needlelike calcium chloroaluminate hydrate together with potassium chloride (bottom, right), as detected by EDS analysis

were detected: the residual calcium aluminate components$\mathrm{CA}$ and $\mathrm{CA}_{2}$, as well as the hydration products, mainly the hexagonal calcium aluminate $\mathrm{CAH}_{10}$ and aluminum hydroxide, some amount of hydrogarnet $\mathrm{C}_{3} \mathrm{AH}_{6}$ and calcium chloroaluminate in the presence of $\mathrm{KCl}$. Calcium silicoaluminate hydrate $\left(\mathrm{C}_{2} \mathrm{ASH}_{8}\right.$ - strätlingite) was not detected by XRD; the phase assemblage remained almost unchanged up to 6-month maturing.

The flow properties of CAC70 pastes with additives (OPC, BPCKD) and admixtures $(\mathrm{KCl})$ were studied by rotation viscometer. However, it was neither possible to add higher amount of by-pass dust nor to process the cement with $\mathrm{KCl}$ of higher concentration than $0.01 \mathrm{~m}$ because of the stiffening of the paste (the rotation of cylinder in the device is then impossible). Therefore ,the $2 \%$ by-pass dust was added and the measurements were limited to the $0.01 \mathrm{~m}$ $\mathrm{KCl}$ solution (Figs. 5, 6). The CAC70 paste becomes generally less workable in the presence of additives/admixtures used in this study; it results not only from the observation during the experiments, but it can be derived from the yield stress data related to the beginning of paste preparation. However, the structure formed in neat CAC70 paste is the strongest, as it can be concluded from the width of hysteresis loop (Fig. 5). In the presence of by-pass dust and $\mathrm{KCl}$ solution, the viscosity is lowered while it is higher in the presence of cement. One can speculate that the viscosity increases because of the fibrous ettringite formation in the presence of gypsum from Portland cement; this effect cannot be observed in case of by-pass dust additive.

The observations of CAC70 pastes under SEM revealed the formation of typical hexagonal platelike crystals of calcium aluminate hydrates in reference CAC sample, occurring together with aluminum hydroxide (Fig. 7). It is possible to find the additional constituents, not detected by XRD (too low content) formed in the pastes in the presence of additives and admixtures (Figs. 7, 8, 9).

\section{Conclusions}

At some low amount of by-pass cement kiln dust, the hydration of high-calcium aluminate cements is accelerated as it results from the calorimetric studies-the shortening of initial dormant period is observed; this effect can be attributed to the joined action of soluble chloride component and active solid cement clinker precursor.

At some low amount of by-pass cement kiln dust (up to $10 \%$ ), the hydration of high-calcium aluminate cements is modified toward the stabilization of hexagonal $\mathrm{CAH}_{10}$ and aluminum hydroxide. The conversion to the regular $\mathrm{C}_{3} \mathrm{AH}_{6}$ seems to be hampered as in case of Portland cement additive.

The rheological properties of CAC paste are modified by a by-pass cement kiln dust toward the improvement of workability, both by chloride (decrease in viscosity) and by clinker (increase of viscosity) component. This is the consequence of microstructure with no large fibrous or platelike forms.

The addition of some percentage of by-pass cement kiln dust as a calcium aluminate material modifying agent can be considered.

Acknowledgements The financial support from the Faculty of Material Science and Ceramics, University of Science and Technology AGH in Cracow, Poland, is greatly acknowledged (tutorial activity No 11.11.160.557) 
Open Access This article is distributed under the terms of the Creative Commons Attribution 4.0 International License (http://creativecommons.org/licenses/by/4.0/), which permits unrestricted use, distribution, and reproduction in any medium, provided you give appropriate credit to the original author(s) and the source, provide a link to the Creative Commons license, and indicate if changes were made.

\section{References}

1. Scrivener KL, Capmas A. Calcium aluminate cements, chapter 13. In: Hewlett PC, editor. Lea's chemistry of cement and concrete. New York: Wiley; 1998.

2. Bensted J. Calcium aluminate cements. In: Bensted J, Barnes P, editors. Structure and performance of cements. 2nd ed. London: CRC Press; 2002. p. 114-38.

3. Gosselin C. Microstructural development of calcium aluminate cement based systems with and without supplementary cementitious materials (Ph.D. Thesis) EPFL. Switzerland; 2009.

4. Nocuń-Wczelik W, Konik Z, Stok A. Heat evolution in hydrated expansive cement systems. J Therm Anal Calorim. 2010;101:527-32.

5. Ping Gu, Beaudoin JJ, Quinn EG, Myers RE. Early strength development and hydration of ordinary Portland cement/calcium aluminate cement pastes. Adv Cem Based Mater. 1997;6:53-8.

6. Gawlicki M, Nocuń-Wczelik W, Bąk Ł. Calorimetry in the studies of cement hydration. Setting and hardening of Portland cementcalcium aluminate cement mixtures. J Therm Anal Calorim. 2010;100:571-6.

7. Nocuń-Wczelik W, Konik Z, Stok A. Blended systems with calcium aluminate and calcium sulphate expansive additives. Constr Build Mater. 2011;25:939-43.

8. Duran A, Sirera R, Pérez-Nicolás M, Navarro-Blasco I, Fernández JM, Alvarez JI. Study of the early hydration of calcium aluminates in the presence of different metallic salts. Cem Concr Res. 2016;81:1-15.

9. Falzone G, Balonis M, Sant G. X-AFm stabilization as a mechanism of bypassing conversion phenomena in calcium aluminate cements. Cem Concr Res. 2015;72:54-68.

10. Pacewska B, Wilińska I, Nowacka M. Studies on the influence of different fly ashes and Portland cement on early hydration of calcium aluminate cement. J Therm Anal Calorim. 2011;106:859-68

11. Pacewska B, Nowacka M, Wilinska I, Kubissa W, Antonovich V. Studies on the influence of spent FCC catalyst on hydration of calcium aluminate cements at ambient temperature. J Therm Anal Calorim. 2011;105:129-40.
12. Hidalgo A, García LJ, Cruz Alonso M, Fernández L, Andrade C. Microstructure development in mixes of calcium aluminate cement with silica fume or fly ash. J Therm Anal Calorim. 2009;96:335-45.

13. Yang HJ, Ann KY, Jung MS. Development of strength for calcium aluminate cement mortars blended with GGBS. Adv Mat Sci Eng. 2019. https://doi.org/10.1155/2019/9896012.

14. Pacewska B, Nowacka M, Aleknevičius M, Antonovič V. Early hydration of calcium aluminate cement blended with spent FCC catalyst at two temperatures. Proc Eng. 2013;57:844-50.

15. Pacewska B, Nowacka M, Antonovič V, Aleknevičius M. Investigation of early hydration of high aluminate cement based binder at different ambient temperature. J Therm Anal Calorim. 2012. https://doi.org/10.1007/s10973-012-2233-6.

16. Siddique R. Utilization of cement kiln dust (CKD) in cement mortar and concrete-an overview. Resour Conserv Recycl. 2006;48:315-38.

17. Nocuń-Wczelik W, Jasińska M, Trybalska B. Kinetics of cement hydration in the presence of some additives and admixtures. Ceram Mater. 2016;68:86-92.

18. Henry-Lanier E, Espinosa B, Eychenne-Baron C. Environmental footprint of calcium aluminate cements (CAC). In: Fentiman C, Mangabhai R, Scrivener K, editors. Calcium aluminates: proceedings of 2014 international conference. 2014. p. 3-16.

19. Sakai E, Sugiyama T, Saito T, Daimon M. Mechanical properties and micro-structures of calcium aluminate based ultra high strength cement. Cem Concr Res. 2010;40:966-70.

20. Nocuń-Wczelik W. Differential calorimetry as a tool in the studies of cement hydration kinetics with sulfate and nitrate solutions. J Therm Anal Calorim. 2017. https://doi.org/10.1007/ s10973-017-6378-1.

21. Romano RCO, Montefusco H, Maciel MH, Pileggi RG. Using isothermal calorimetry, X-ray diffraction, thermogravimetry and FTIR to monitor the hydration reaction of Portland cements associated with red mud as a supplementary material. J Therm Anal Calorim. 2019. https://doi.org/10.1007/s10973-019-08095-x.

22. Trusilewicz LN, Nocuń-Wczelik W, Górak P, Woyciechowski P. Early hydration calorimetric study of the sewage sludge incinerated waste streams Portland cement-based binders. J Therm Anal Calorim. 2019. https://doi.org/10.1007/s10973-019-08784-7.

23. Litwinek E, Madej D. Structure, microstructure and thermal stability characterizations of $\mathrm{C}_{3} \mathrm{AH}_{6}$ synthesized from different precursors through hydration. J Therm Anal Calorim. 2019. https:// doi.org/10.1007/s10973-019-08784-7.

Publisher's Note Springer Nature remains neutral with regard to jurisdictional claims in published maps and institutional affiliations. 